\title{
A modal pushover analysis procedure for estimating seismic demands for buildings
}

\author{
Anil K. Chopra ${ }^{1, *, \dagger}$ and Rakesh K. Goel ${ }^{2}$ \\ ${ }^{1}$ Department of Civil and Environmental Engineering, University of California at Berkeley, Berkeley, \\ CA, 94720-1710, U.S.A. \\ ${ }^{2}$ Department of Civil and Environmental Engineering, California Polytechnic State University, San Luis Obispo, \\ CA, U.S.A.
}

\begin{abstract}
SUMMARY
Developed herein is an improved pushover analysis procedure based on structural dynamics theory, which retains the conceptual simplicity and computational attractiveness of current procedures with invariant force distribution. In this modal pushover analysis (MPA), the seismic demand due to individual terms in the modal expansion of the effective earthquake forces is determined by a pushover analysis using the inertia force distribution for each mode. Combining these 'modal' demands due to the first two or three terms of the expansion provides an estimate of the total seismic demand on inelastic systems. When applied to elastic systems, the MPA procedure is shown to be equivalent to standard response spectrum analysis (RSA). When the peak inelastic response of a 9-storey steel building determined by the approximate MPA procedure is compared with rigorous non-linear response history analysis, it is demonstrated that MPA estimates the response of buildings responding well into the inelastic range to a similar degree of accuracy as RSA in estimating peak response of elastic systems. Thus, the MPA procedure is accurate enough for practical application in building evaluation and design. Copyright (C) 2001 John Wiley \& Sons, Ltd.
\end{abstract}

KEY WORDS: building evaluation and retrofit; modal analysis; pushover; seismic demands

\section{INTRODUCTION}

Estimating seismic demands at low performance levels, such as life safety and collapse prevention, requires explicit consideration of inelastic behaviour of the structure. While non-linear response history analysis (RHA) is the most rigorous procedure to compute seismic demands, current civil engineering practice prefers to use the non-linear static procedure (NSP) or pushover analysis in FEMA-273 [1]. The seismic demands are computed by non-linear static

\footnotetext{
* Correspondence to: Anil K. Chopra, Department of Civil and Environmental Engineering, University of California at Berkeley, Berkeley, CA 94720-1710, U.S.A.

† E-mail: chopra@ce.berkeley.edu
} 
analysis of the structure subjected to monotonically increasing lateral forces with an invariant height-wise distribution until a predetermined target displacement is reached. Both the force distribution and target displacement are based on the assumption that the response is controlled by the fundamental mode and that the mode shape remains unchanged after the structure yields.

Obviously, after the structure yields, both assumptions are approximate, but investigations [2-9] have led to good estimates of seismic demands. However, such satisfactory predictions of seismic demands are mostly restricted to low- and medium-rise structures provided the inelastic action is distributed throughout the height of the structure $[7,10]$.

None of the invariant force distributions can account for the contributions of higher modes to response, or for a redistribution of inertia forces because of structural yielding and the associated changes in the vibration properties of the structure. To overcome these limitations, several researchers have proposed adaptive force distributions that attempt to follow more closely the time-variant distributions of inertia forces $[5,11,12]$. While these adaptive force distributions may provide better estimates of seismic demands [12], they are conceptually complicated and computationally demanding for routine application in structural engineering practice. Attempts have also been made to consider more than the fundamental vibration mode in pushover analysis [12-16].

The principal objective of this investigation is to develop an improved pushover analysis procedure based on structural dynamics theory that retains the conceptual simplicity and computational attractiveness of the procedure with invariant force distribution-now common in structural engineering practice. First, we develop a modal pushover analysis (MPA) procedure for linearly elastic buildings and demonstrate that it is equivalent to the well-known response spectrum analysis (RSA) procedure. The MPA procedure is then extended to inelastic buildings, the underlying assumptions and approximations are identified, and the errors in the procedure relative to a rigorous non-linear RHA are documented.

\section{DYNAMIC AND PUSHOVER ANALYSIS PROCEDURES: ELASTIC BUILDINGS}

\section{Modal response history analysis}

The differential equations governing the response of a multistorey building to horizontal earthquake ground motion $\ddot{u}_{g}(t)$ are as follows:

$$
\mathbf{m u ̈}+\mathbf{c u}+\mathbf{k u}=-\mathbf{m} \ddot{u}_{g}(t)
$$

where $\mathbf{u}$ is the vector of $N$ lateral floor displacements relative to the ground, $\mathbf{m}, \mathbf{c}$, and $\mathbf{k}$ are the mass, classical damping, and lateral stiffness matrices of the systems; each element of the influence vector $\boldsymbol{\imath}$ is equal to unity.

The right-hand side of Equation (1) can be interpreted as effective earthquake forces:

$$
\mathbf{p}_{\mathrm{eff}}(t)=-\mathbf{m} \boldsymbol{\imath} \ddot{u}_{g}(t)
$$

The spatial distribution of these effective forces over the height of the building is defined by the vector $\mathbf{s}=\mathbf{m} \boldsymbol{\imath}$ and their time variation by $\ddot{u}_{g}(t)$. This force distribution can be expanded 
as a summation of modal inertia force distribution $\mathbf{s}_{n}[17$, Section 13.2]:

$$
\mathbf{m} \boldsymbol{\imath}=\sum_{n=1}^{N} \mathbf{s}_{n}=\sum_{n=1}^{N} \Gamma_{n} \mathbf{m} \phi_{n}
$$

where $\phi_{n}$ is the $n$th natural vibration mode of the structure, and

$$
\Gamma_{n}=\frac{L_{n}}{M_{n}}, \quad L_{n}=\boldsymbol{\phi}_{n}^{T} \mathbf{m} \boldsymbol{\imath}, \quad M_{n}=\boldsymbol{\phi}_{n}^{T} \mathbf{m} \phi_{n}
$$

The effective earthquake forces can then be expressed as

$$
\mathbf{p}_{\text {eff }}(t)=\sum_{n=1}^{N} \mathbf{p}_{\mathrm{eff}, n}(t)=\sum_{n=1}^{N}-\mathbf{s}_{n} \ddot{u}_{g}(t)
$$

The contribution of the $n$th mode to $\mathbf{s}$ and to $\mathbf{p}_{\text {eff }}(t)$ are:

$$
\begin{aligned}
\mathbf{s}_{n} & =\Gamma_{n} \mathbf{m} \boldsymbol{\phi}_{n} \\
\mathbf{p}_{\mathrm{eff},},(t) & =-\mathbf{s}_{n} \ddot{u}_{g}(t)
\end{aligned}
$$

The response of the MDF system to $\mathbf{p}_{\text {eff, }, n}(t)$ is entirely in the $n$ th-mode, with no contributions from other modes. Then the floor displacements are

$$
\mathbf{u}_{n}(t)=\phi_{n} q_{n}(t)
$$

where the modal co-ordinate $q_{n}(t)$ is governed by

$$
\ddot{q}_{n}+2{ }_{n} \omega_{n} \dot{q}_{n}+\omega_{n}^{2} q_{n}=-\Gamma_{n} \ddot{u}_{g}(t)
$$

in which $\omega_{n}$ is the natural vibration frequency and ${ }_{n}$ is the damping ratio for the $n$th mode. The solution $q_{n}$ of Equation (8) is given by

$$
q_{n}(t)=\Gamma_{n} D_{n}(t)
$$

where $D_{n}(t)$ is governed by the equation of motion for the $n$ th-mode linear SDF system, an SDF system with vibration properties - natural frequency $\omega_{n}$ and damping ratio ${ }_{n}$ - of the $n$ th-mode of the MDF system, subjected to $\ddot{u}_{g}(t)$ :

$$
\ddot{D}_{n}+2{ }_{n} \omega_{n} \dot{D}_{n}+\omega_{n}^{2} D_{n}=-\ddot{u}_{g}(t)
$$

Substituting Equation (9) into Equation (7) gives the floor displacements

$$
\mathbf{u}_{n}(t)=\Gamma_{n} \boldsymbol{\phi}_{n} D_{n}(t)
$$

Any response quantity $r(t)$ - storey drifts, internal element forces, etc.—can be expressed as

$$
r_{n}(t)=r_{n}^{\mathrm{st}} A_{n}(t)
$$

where $r_{n}^{\text {st }}$ denotes the modal static response, the static value of $r$ due to external forces $\mathbf{s}_{n}$, and

$$
A_{n}(t)=\omega_{n}^{2} D_{n}(t)
$$




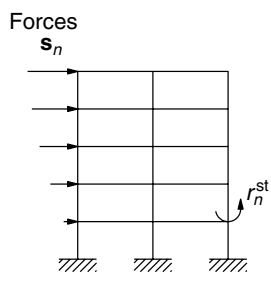

(a) Static Analysis of

Structure

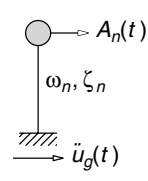

(b) Dynamic Analysis of
SDF System

Figure 1. Conceptual explanation of modal RHA of elastic MDF systems.

is the pseudo-acceleration response of the $n$ th-mode SDF system [17, Section 13.1]. The two analyses that lead to $r_{n}^{\text {st }}$ and $A_{n}(t)$ are shown schematically in Figure 1. Equations (11) and (12) represent the response of the MDF system to $\mathbf{p}_{\mathrm{eff}, n}(t)$ [Equation (6b)]. Therefore, the response of the system to the total excitation $\mathbf{p}_{\text {eff }}(t)$ is

$$
\begin{gathered}
\mathbf{u}(t)=\sum_{n=1}^{N} \mathbf{u}_{n}(t)=\sum_{n=1}^{N} \Gamma_{n} \boldsymbol{\phi}_{n} D_{n}(t) \\
r(t)=\sum_{n=1}^{N} r_{n}(t)=\sum_{n=1}^{N} r_{n}^{\mathrm{st}} A_{n}(t)
\end{gathered}
$$

This is the classical modal RHA procedure: Equation (8) is the standard modal equation governing $q_{n}(t)$, Equations (11) and (12) define the contribution of the $n$ th-mode to the response, and Equations (14) and (15) reflect combining the response contributions of all modes. However, these standard equations have been derived in an unconventional way. In contrast to the classical derivation found in textbooks (e.g. Reference [17, Sections 12.4 and 13.1.3]), we have used the modal expansion of the spatial distribution of the effective earthquake forces. This concept will provide a rational basis for the MPA procedure developed later.

\section{Modal response spectrum analysis}

The peak value $r_{n o}$ of the $n$ th-mode contribution $r_{n}(t)$ to response $r(t)$ is determined from

$$
r_{n o}=r_{n}^{\text {st }} A_{n}
$$

where $A_{n}$ is the ordinate $A\left(T_{n}, \zeta_{n}\right)$ of the pseudo-acceleration response (or design) spectrum for the $n$ th-mode SDF system, and $T_{n}=2 \pi / \omega_{n}$ is the $n$th natural vibration period of the MDF system.

The peak modal responses are combined according to the square-root-of-sum-of-squares (SRSS) or the complete quadratic combination (CQC) rules. The SRSS rule, which is valid for structures with well-separated natural frequencies such as multistorey buildings with symmetric plan, provides an estimate of the peak value of the total response:

$$
r_{o} \approx\left(\sum_{n=1}^{N} r_{n o}^{2}\right)^{1 / 2}
$$




\section{Modal pushover analysis}

To develop a pushover analysis procedure consistent with RSA, we observe that static analysis of the structure subjected to lateral forces

$$
\mathbf{f}_{n o}=\Gamma_{n} \mathbf{m} \phi_{n} A_{n}
$$

will provide the same value of $r_{n o}$, the peak $n$ th-mode response as in Equation (16) [17, Section 13.8.1]. Alternatively, this response value can be obtained by static analysis of the structure subjected to lateral forces distributed over the building height according to

$$
\mathbf{s}_{n}^{*}=\mathbf{m} \phi_{n}
$$

with the structure pushed to the roof displacement, $u_{r n o}$, the peak value of the roof displacement due to the $n$ th-mode, which from Equation (11) is

$$
u_{r n o}=\Gamma_{n} \quad{ }_{r n} D_{n}
$$

where $D_{n}=A_{n} / \omega_{n}^{2}$; obviously $D_{n}$ or $A_{n}$ are readily available from the response (or design) spectrum.

The peak modal responses $r_{n o}$, each determined by one pushover analysis, can be combined according to Equation (17) to obtain an estimate of the peak value $r_{o}$ of the total response. This MPA for linearly elastic systems is equivalent to the well-known RSA procedure.

\section{DYNAMIC AND PUSHOVER ANALYSIS PROCEDURES: INELASTIC BUILDINGS}

\section{Response history analysis}

For each structural element of a building, the initial loading curve can be idealized appropriately (e.g. bilinear with or without degradation) and the unloading and reloading curves differ from the initial loading branch. Thus, the relations between lateral forces $\mathbf{f}_{s}$ at the $N$ floor levels and the lateral displacements $\mathbf{u}$ are not single-valued, but depend on the history of the displacements:

$$
\mathbf{f}_{s}=\mathbf{f}_{s}(\mathbf{u}, \operatorname{sign} \dot{\mathbf{u}})
$$

With this generalization for inelastic systems, Equation (1) becomes

$$
\mathbf{m u ̈}+\mathbf{c u}+\mathbf{f}_{s}(\mathbf{u}, \operatorname{sign} \dot{\mathbf{u}})=-\mathbf{m} \mathbf{\imath} \ddot{u}_{g}(t)
$$

The standard approach is to directly solve these coupled equations, leading to the 'exact' non-linear RHA.

Although classical modal analysis is not valid for inelastic systems, it will be used next to transform Equation (22) to the modal co-ordinates of the corresponding linear system. Each structural element of this elastic system is defined to have the same stiffness as the initial stiffness of the structural element of the inelastic system. Both systems have the same mass and damping. Therefore, the natural vibration periods and modes of the corresponding linear system are the same as the vibration properties of the inelastic system undergoing small oscillations (within the linear range). 
Expanding the displacements of the inelastic system in terms of the natural vibration modes of the corresponding linear system, we get

$$
\mathbf{u}(t)=\sum_{n=1}^{N} \boldsymbol{\phi}_{n} q_{n}(t)
$$

Substituting Equation (23) into Equation (22), premultiplying by $\boldsymbol{\phi}_{n}^{T}$, and using the mass- and classical damping-orthogonality property of modes gives

$$
\ddot{q}_{n}+2{ }_{n} \omega_{n} \dot{q}_{n}+\frac{F_{s n}}{M_{n}}=-\Gamma_{n} \ddot{u}_{g}(t), \quad n=1,2, \ldots, N
$$

where the only term that differs from Equation (8) involves

$$
F_{s n}=F_{s n}(\mathbf{q}, \operatorname{sign} \dot{\mathbf{q}})=\boldsymbol{\phi}_{n}^{T} \mathbf{f}_{s}(\mathbf{u}, \operatorname{sign} \dot{\mathbf{u}})
$$

This resisting force depends on all modal co-ordinates $q_{n}(t)$, implying coupling of modal co-ordinates because of yielding of the structure.

Equation (24) represents $N$ equations in the modal co-ordinates $q_{n}$. Unlike Equation (8) for linearly elastic systems, these equations are coupled for inelastic systems. Simultaneously solving these coupled equations and using Equation (23) will, in principle, give the same results for $\mathbf{u}(t)$ as obtained directly from Equation (22). However, Equation (24) is rarely used because it offers no particular advantage over Equation (22).

\section{Uncoupled modal response history analysis}

Neglecting the coupling of the $N$ equations in modal co-ordinates [Equation (24)] leads to the uncoupled modal response history analysis (UMRHA) procedure. This approximate RHA procedure was used as a basis for developing an MPA procedure for inelastic systems.

The spatial distribution $\mathbf{s}$ of the effective earthquake forces is expanded into the modal contributions $\mathbf{s}_{n}$ according to Equation (3), where $\boldsymbol{\phi}_{n}$ are now the modes of the corresponding linear system. The equations governing the response of the inelastic system to $\mathbf{p}_{\mathrm{eff}, n}(t)$ given by Equation (6b) are

$$
\mathbf{m u ̈}+\mathbf{c} \dot{\mathbf{u}}+\mathbf{f}_{s}(\mathbf{u}, \operatorname{sign} \dot{\mathbf{u}})=-\mathbf{s}_{n} \ddot{u}_{g}(t)
$$

The solution of Equation (26) for inelastic systems will no longer be described by Equation (7) because 'modes' other than the $n$ th-'mode' will also contribute to the solution. However, because for linear systems $q_{\mathrm{r}}(t)=0$ for all modes other than the $n$ th-mode, it is reasonable to expect that the $n$ th-'mode' should be dominant even for inelastic systems.

This assertion is illustrated numerically in Figure 2 for a 9-storey SAC steel building described in Appendix A. Equation (26) was solved by non-linear RHA, and the resulting roof displacement history was decomposed into its 'modal' components. The beams in all storeys except two yield when subjected to the strong excitation of $1.5 \times$ El Centro ground motion, and the modes other than the $n$ th-mode contribute to the response. The second and third modes start responding to excitation $\mathbf{p}_{\mathrm{eff}, 1}(t)$ the instant the structure first yields at about $5.2 \mathrm{~s}$; however, their contributions to the roof displacement are only 7 and 1 per cent, respectively, of the first mode response [Figure 2(a)]. The first and third modes start responding to excitation $\mathbf{p}_{\text {eff, } 2}(t)$ the instant the structure first yields at about $4.2 \mathrm{~s}$; however, their contributions to 

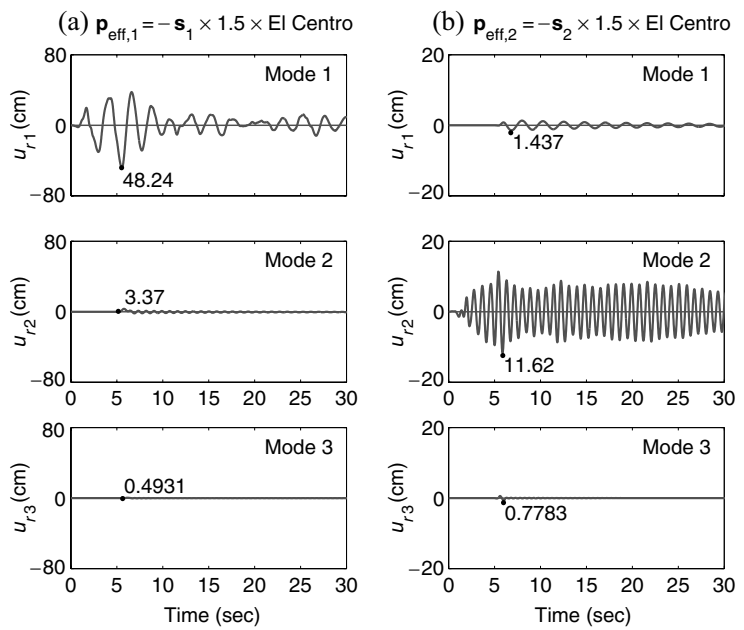

Figure 2. Modal decomposition of the roof displacement for first three modes due to $1.5 \times \mathrm{El}$ Centro ground motion: (a) $\mathbf{p}_{\mathrm{eff}, 1}(t)=-\mathbf{s}_{1} \times 1.5 \times$ El Centro; (b) $\mathbf{p}_{\mathrm{eff}, 2}(t)=-\mathbf{s}_{2} \times 1.5 \times \mathrm{El}$ Centro ground motion.

the roof displacement of the second mode response (Figure 2(b)) are 12 and 7 per cent, respectively, of the second mode response [Figure 2(b)].

Approximating the response of the structure to excitation $\mathbf{p}_{\text {eff, }, n}(t)$ by Equation (7), substituting Equation (7) into Equation (26), and premultiplying by $\phi_{n}^{T}$ gives Equation (24) except for the important approximation that $F_{s n}$ now depends only on one modal co-ordinate, $q_{n}$ :

$$
F_{s n}=F_{s n}\left(q_{n}, \operatorname{sign} \dot{q}_{n}\right)=\boldsymbol{\phi}_{n}^{T} \mathbf{f}_{s}\left(q_{n}, \operatorname{sign} \dot{q}_{n}\right)
$$

With this approximation, the solution of Equation (24) can be expressed by Equation (9), where $D_{n}(t)$ is governed by

$$
\ddot{D}_{n}+2{ }_{n} \omega_{n} \dot{D}_{n}+\frac{F_{s n}}{L_{n}}=-\ddot{u}_{g}(t)
$$

and

$$
F_{s n}=F_{s n}\left(D_{n}, \operatorname{sign} \dot{D}_{n}\right)=\boldsymbol{\phi}_{n}^{\mathrm{T}} \mathbf{f}_{s}\left(D_{n}, \operatorname{sign} \dot{D}_{n}\right)
$$

is related to $F_{s n}\left(q_{n}, \operatorname{sign} \dot{q}_{n}\right)$ because of Equation (9).

Equation (28) may be interpreted as the governing equation for the $n$ th-'mode' inelastic SDF system, an SDF system with (1) small amplitude vibration properties - natural frequency $\omega_{n}$ and damping ratio $n$ - of the $n$ th-mode of the corresponding linear MDF system; and (2) $F_{s n} / L_{n}-D_{n}$ relation between resisting force $F_{s n} / L_{n}$ and modal co-ordinate $D_{n}$ defined by Equation (29). Although Equation (24) can be solved in its original form, Equation (28) can be solved conveniently by standard software because it is of the same form as the standard equation for an SDF system, and the peak value of $D_{n}(t)$ can be estimated from the inelastic response (or design) spectrum [17, Sections 7.6 and 7.12.1]. Introducing the $n$ th-'mode' inelastic SDF system also permitted extension of the well-established concepts for elastic systems to inelastic 


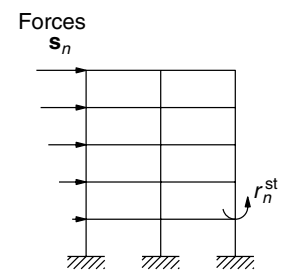

(a) Static Analysis of

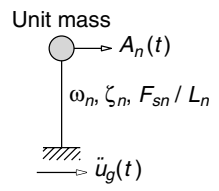

(b) Dynamic Analysis of Inelastic SDF System

Figure 3. Conceptual explanation of uncoupled modal RHA of inelastic MDF systems.

systems; compare Equations (24) and (28) to Equations (8) and (10), and note that Equation (9) applies to both systems. $\ddagger$

Solution of the non-linear Equation (28) formulated in this manner provides $D_{n}(t)$, which when substituted into Equation (11) gives the floor displacements of the structure associated with the $n$ th-'mode' inelastic SDF system. Any floor displacement, storey drift, or another deformation response quantity $r_{n}(t)$ is given by Equations (12) and (13), where $A_{n}(t)$ is now the pseudo-acceleration response of the $n$ th-'mode' inelastic SDF system. The two analyses that lead to $r_{n}^{\text {st }}$ and $A_{n}(t)$ for the inelastic system are shown schematically in Figure 3. Equations (12) and (13) now represent the response of the inelastic MDF system to $\mathbf{p}_{\text {eff, } n}(t)$, the $n$ th-mode contribution to $\mathbf{p}_{\text {eff }}(t)$. Therefore, the response of the system to the total excitation $\mathbf{p}_{\text {eff }}(t)$ is given by Equations (14) and (15). This is the UMRHA procedure.

Underlying assumptions and accuracy. Using the $3.0 \times$ El Centro ground motion for both analyses, the approximate solution of Equation (26) by UMRHA is compared with the 'exact' solution by non-linear RHA. This intense excitation was chosen to ensure that the structure is excited well beyond its linear elastic limit. Such comparison for roof displacement and top-storey drift is presented in Figures 4 and 5, respectively. The errors are slightly larger in drift than in displacement, but even for this very intense excitation, the errors in either response quantity are only a few per cent.

These errors arise from the following assumptions and approximations: (i) the coupling between modal co-ordinates $q_{n}(t)$ arising from yielding of the system [recall Equations (24) and (25)] is neglected; (ii) the superposition of responses to $\mathbf{p}_{\mathrm{eff}, n}(t)(n=1,2, \ldots, N)$ according to Equation (15) is strictly valid only for linearly elastic systems; and (iii) the $F_{s n} / L_{n}-D_{n}$ relation is approximated by a bilinear curve to facilitate solution of Equation (28) in UMRHA. Although approximations are inherent in this UMRHA procedure, when specialized for linearly elastic systems it is identical to the RHA procedure described earlier for such systems. The overall errors in the UMRHA procedure are documented in the examples presented in a later section.

Properties of the nth-mode inelastic SDF system. How is the $F_{s n} / L_{n}-D_{n}$ relation to be determined in Equation (28) before it can be solved? Because Equation (28) governing $D_{n}(t)$ is based on Equation (7) for floor displacements, the relationship between lateral forces $\mathbf{f}_{s}$

$\ddagger$ Equivalent inelastic SDF systems have been defined differently by other researchers $[18,19]$. 
(a) Nonlinear RHA
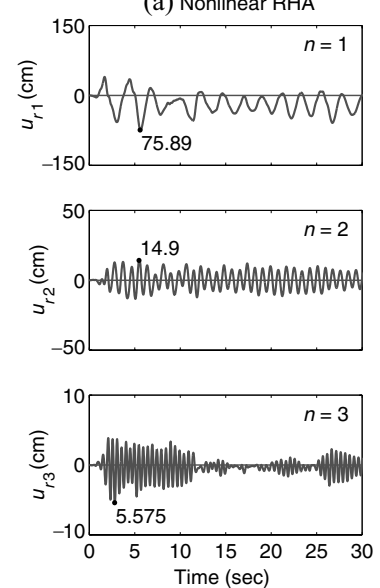

(b) UMRHA
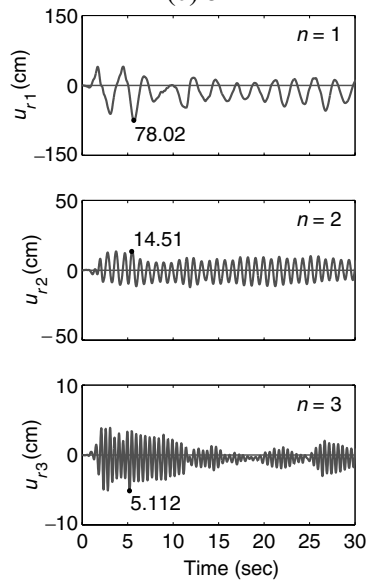

Figure 4. Comparison of an approximate roof displacement from UMRHA with exact solution by non-linear RHA for $\mathbf{p}_{\text {eff, },}(t)=-\mathbf{s}_{n} \ddot{u}_{g}(t), n=1,2$ and 3 , where $\ddot{u}_{g}(t)=$ $3.0 \times$ El Centro ground motion.

(a) Nonlinear RHA
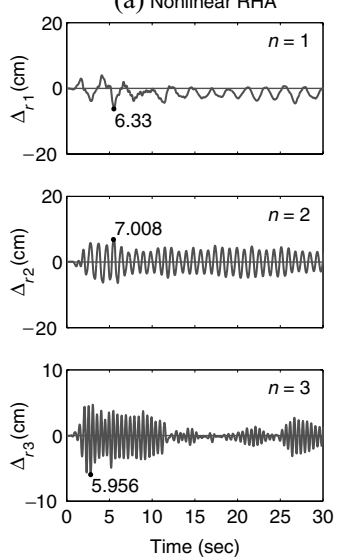

(b) UMRHA
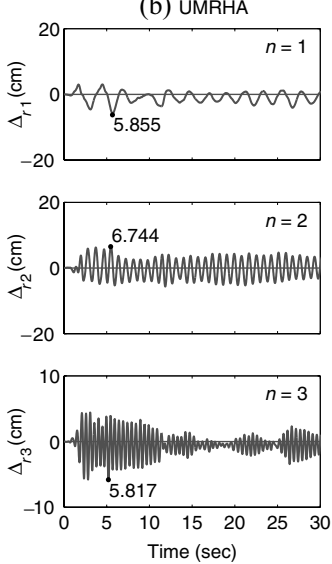

Figure 5. Comparison of approximate storey drift from UMRHA with exact solution by non-linear RHA for $\mathbf{p}_{\text {eff }, n}(t)=-\mathbf{s}_{n} \ddot{u}_{g}(t), n=1,2$ and 3 , where $\ddot{u}_{g}(t)=3.0 \times$ El Centro motion.

and $D_{n}$ in Equation (29) should be determined by non-linear static analysis of the structure as the structure undergoes displacements $\mathbf{u}=D_{n} \boldsymbol{\phi}_{n}$ with increasing $D_{n}$. Although most commercially available software cannot implement such displacement-controlled analysis, it can conduct a force-controlled non-linear static analysis with an invariant distribution of lateral forces. Therefore, we impose this constraint in developing the UMRHA procedure in this section and MPA in the next section.

What is an appropriate invariant distribution of lateral forces to determine $F_{s n}$ ? For an inelastic system no invariant distribution of forces can produce displacements proportional 

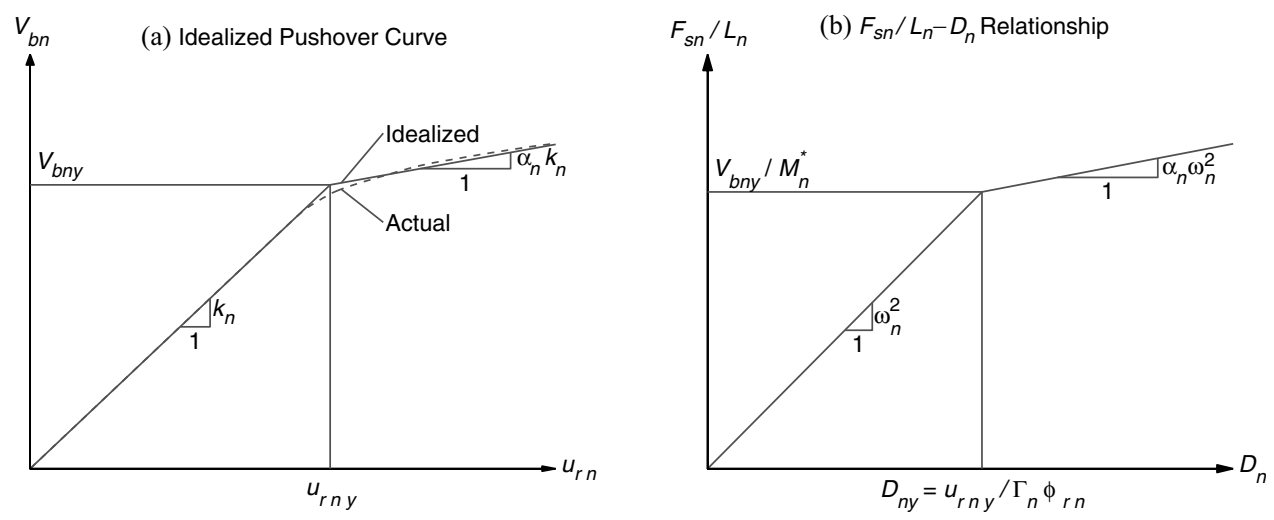

Figure 6. Properties of the $n$ th-'mode' inelastic SDF system from the pushover curve.

to $\phi_{n}$ at all displacements or force levels. However, before any part of the structure yields, the only force distribution that produces displacements proportional to $\phi_{n}$ is given by Equation (19). Therefore, this distribution seems to be a rational choice-even after the structure yields - to determine $F_{s n}$ in Equation (29). When implemented by commercially available software, such non-linear static analysis provides the so-called pushover curve, which is different than the $F_{s n} / L_{n}-D_{n}$ curve. The structure is pushed using the force distribution of Equation (19) to some predetermined roof displacement, and the base shear $V_{b n}$ is plotted against roof displacement $u_{r n}$. A bilinear idealization of this pushover curve for the $n$ th-'mode' is shown in Figure 6(a). At the yield point, the base shear is $V_{b n y}$ and roof displacement is $u_{r n y}$.

How to convert this $V_{b n}-u_{r n}$ pushover curve to the $F_{s n} / L_{n}-D_{n}$ relation? The two sets of forces and displacements are related as follows:

$$
F_{s n}=\frac{V_{b n}}{\Gamma_{n}}, \quad D_{n}=\frac{u_{r n}}{\Gamma_{n} r n}
$$

Equation (30) enables conversion of the pushover curve to the desired $F_{s n} / L_{n}-D_{n}$ relation shown in Figure 5(b), where the yield values of $F_{s n} / L_{n}$ and $D_{n}$ are

$$
\frac{F_{s n y}}{L_{n}}=\frac{V_{b n y}}{M_{n}^{*}}, \quad D_{n \mathrm{y}}=\frac{u_{r n \mathrm{y}}}{\Gamma_{n} r n}
$$

in which $M_{n}^{*}=L_{n} \Gamma_{n}$ is the effective modal mass [17, Section 13.2.5]. The two are related through

$$
\frac{F_{\text {sny }}}{L_{n}}=\omega_{n}^{2} D_{n y}
$$

implying that the initial slope of the bilinear curve in Figure 6(b) is $\omega_{n}^{2}$. Knowing $F_{\text {sny }} / L_{n}$ and $D_{n y}$ from Equation (31), the elastic vibration period $T_{n}$ of the $n$ th-'mode' inelastic SDF system is computed from

$$
T_{n}=2\left(\frac{L_{n} D_{n y}}{F_{s n y}}\right)^{1 / 2}
$$


This value of $T_{n}$, which may differ from the period of the corresponding linear system, should be used in Equation (28). In contrast, the initial slope of the pushover curve in Figure 6(a) is $k_{n}=\omega_{n}^{2} L_{n}$, which is not a meaningful quantity.

\section{Modal pushover analysis}

Next a pushover analysis procedure is presented to estimate the peak response $r_{n o}$ of the inelastic MDF system to effective earthquake forces $\mathbf{p}_{\text {eff, } n}(t)$. Consider a non-linear static analysis of the structure subjected to lateral forces distributed over the building height according to $\mathbf{s}_{n}^{*}$ [Equation (19)] with structure pushed to the roof displacement $u_{r n o}$. This value of the roof displacement is given by Equation (20) where $D_{n}$, the peak value of $D_{n}(t)$, is now determined by solving Equation (28), as described earlier; alternatively, it can be determined from the inelastic response (or design) spectrum [17, Sections 7.6 and 7.12]. At this roof displacement, the pushover analysis provides an estimate of the peak value $r_{n o}$ of any response $r_{n}(t)$ : floor displacements, storey drifts, joint rotations, plastic hinge rotations, etc.

This pushover analysis, although somewhat intuitive for inelastic buildings, seems rational for two reasons. First, pushover analysis for each 'mode' provides the exact modal response for elastic buildings and the overall procedure, as demonstrated earlier, provides results that are identical to the well-known RSA procedure. Second, the lateral force distribution used appears to be the most rational choice among all invariant distribution of forces.

The response value $r_{n o}$ is an estimate of the peak value of the response of the inelastic system to $\mathbf{p}_{\text {eff, } n}(t)$, governed by Equation (26). As shown earlier for elastic systems, $r_{n o}$ also represents the exact peak value of the $n$ th-mode contribution $r_{n}(t)$ to response $r(t)$. Thus, we will refer to $r_{n o}$ as the peak 'modal' response even in the case of inelastic systems.

The peak 'modal' responses $r_{n o}$, each determined by one pushover analysis, is combined using an appropriate modal combination rule, e.g. Equation (17), to obtain an estimate of the peak value $r_{o}$ of the total response. This application of modal combination rules to inelastic systems obviously lacks a theoretical basis. However, it provides results for elastic buildings that are identical to the well-known RSA procedure described earlier.

\section{COMPARATIVE EVALUATION OF ANALYSIS PROCEDURES}

The 'exact' response of the 9-storey SAC building described earlier is determined by the two approximate methods, UMRHA and MPA, and compared with the 'exact' results of a rigorous non-linear RHA using the DRAIN-2DX computer program [20]. Gravity-load (and P-delta) effects are excluded from all analyses presented in this paper. However, these effects were included in Chopra and Goel [21]. To ensure that this structure responds well into the inelastic range, the El Centro ground motion is scaled up a factor varying from 1.0 to 3.0. The first three vibration modes and periods of the building for linearly elastic vibration are shown in Figure 7. The vibration periods for the first three modes are 2.27, 0.85, and $0.49 \mathrm{~s}$, respectively. The force distribution $\mathbf{s}_{n}^{*}$ for the first three modes are shown in Figure 8 . These force distributions will be used in the pushover analysis to be presented later.

\section{Uncoupled modal response history analysis}

The structural response to $1.5 \times$ the El Centro ground motion including the response contributions associated with three 'modal' inelastic SDF systems, determined by the UMRHA 


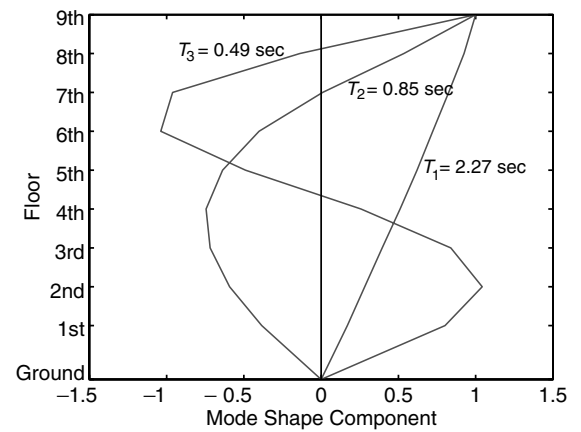

Figure 7. First three natural-vibration periods and modes of the 9-storey building.

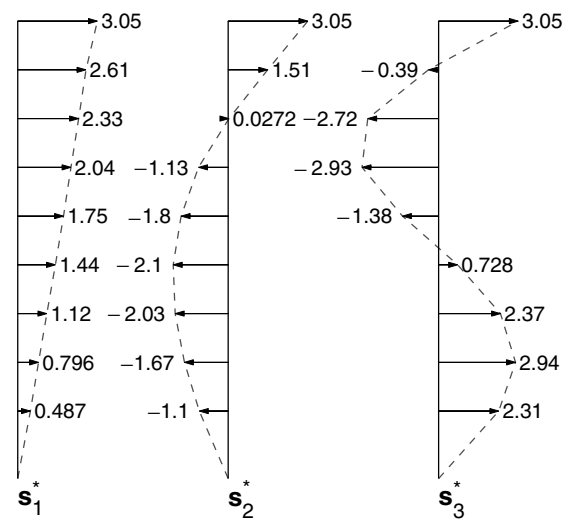

Figure 8. Force distributions $\mathbf{s}_{n}^{*}=\mathbf{m} \phi_{n}, n=1,2$ and 3.

procedure, is presented next. Figure 9 shows the individual 'modal' responses, the combined response due to three 'modes', and the 'exact' values from non-linear RHA for the roof displacement and top-storey drift. The peak values of response are as noted; in particular, the peak roof displacement due to each of the three 'modes', is $u_{\mathrm{r} 10}=48.3 \mathrm{~cm}, u_{\mathrm{r} 20}=11.7 \mathrm{~cm}$ and $u_{\mathrm{r} 30}=2.53 \mathrm{~cm}$. The peak values of floor displacements and storey drifts including one, two, and three modes are compared with the 'exact' values in Figure 10 and the errors in the approximate results are shown in Figure 11.

Observe that errors tend to decrease as response contributions of more 'modes' are included, although the trends are not as systematic as when the system remained elastic [22]. This is to be expected because in contrast to classical modal analysis, the UMRHA procedure lacks a rigorous theory. This deficiency also implies that, with, say, three 'modes' included, the response is much less accurate if the system yields significantly versus if the system remains within the elastic range [22]. However, for a fixed number of 'modes' included, the errors in storey drifts are larger compared to floor displacements, just as for elastic systems.

Next we investigate how the errors in the UMRHA vary with the deformation demands imposed by the ground motion, in particular, the degree to which the system deforms beyond its elastic limit. For this purpose the UMRHA and exact analyses were repeated for ground 
(a) Roof Displacement
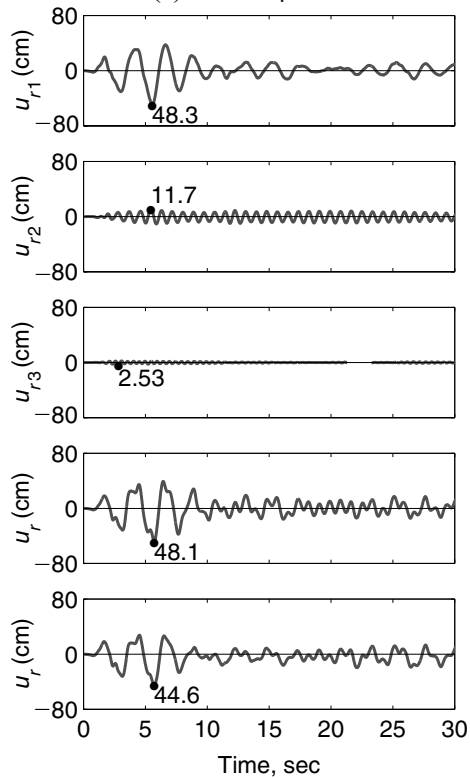

(b) Top Story Drift
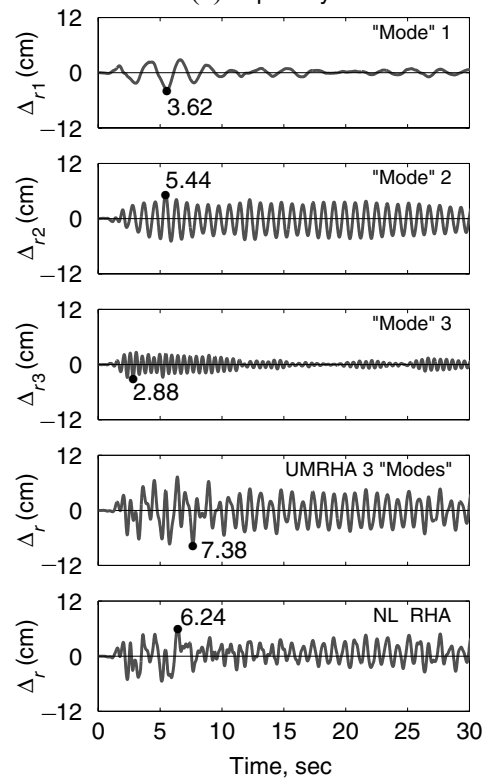

Figure 9. Response histories of roof displacement and top-storey drift due to $1.5 \times$ El Centro ground motion: individual 'modal' responses and combined response from UMRHA, and total response from non-linear RHA.

(a) Floor Displacements

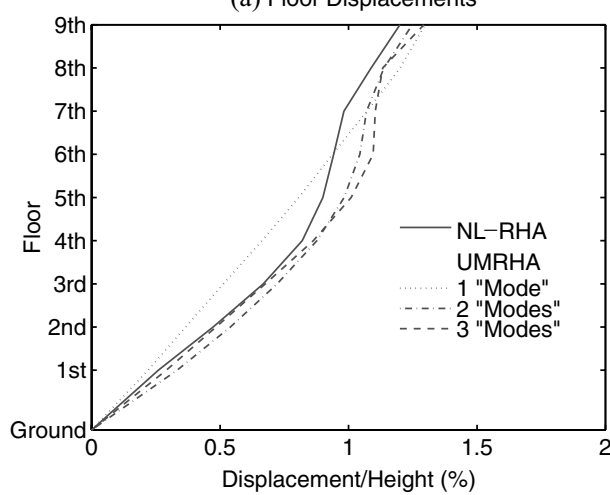

(b) Story Drift Ratios

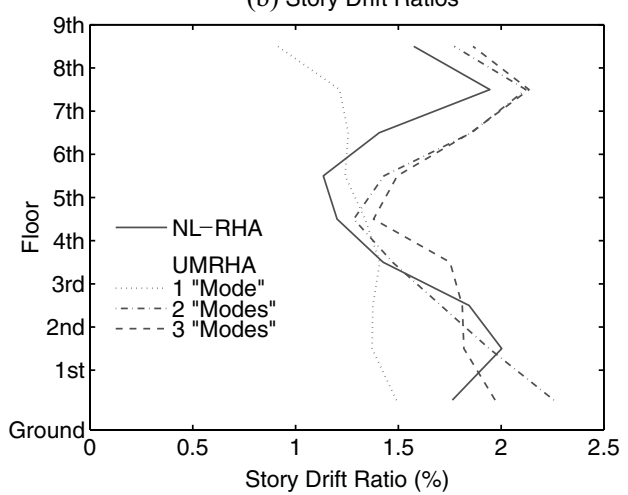

Figure 10. Height-wise variation of floor displacements and storey drift ratios from UMRHA and non-linear RHA for $1.5 \times$ El Centro ground motion.

motions of varying intensity. These excitations were defined by the El Centro ground motion multiplied by $0.25,0.5,0.75,0.85,1.0,1.5,2.0$, and 3.0. For each excitation, the errors in responses computed by UMRHA including three 'modes' relative to the 'exact' response were determined. 
(a) Floor Displacements

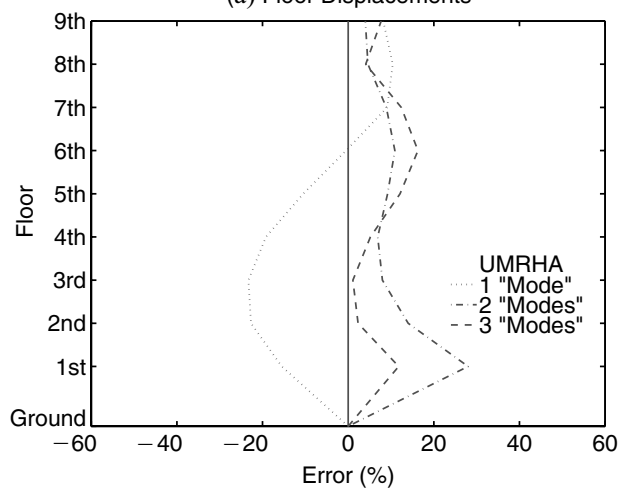

(b) Story Drift Ratios

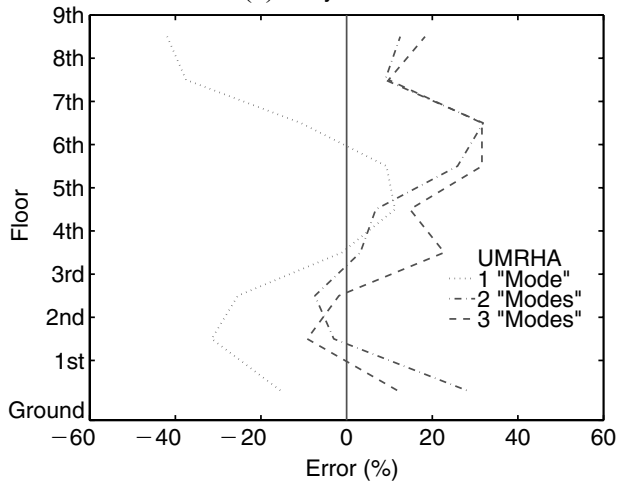

Figure 11. Height-wise variation of error in floor displacements and storey drifts estimated by UMRHA including one, two or three 'modes' for $1.5 \times$ El Centro ground motion.

(a) Floor Displacements

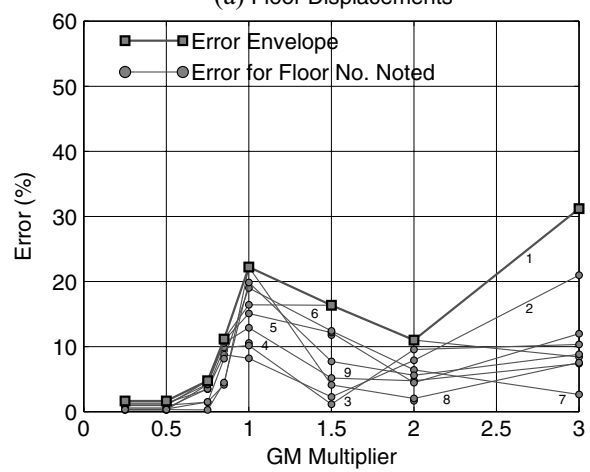

(b) Story Drifts

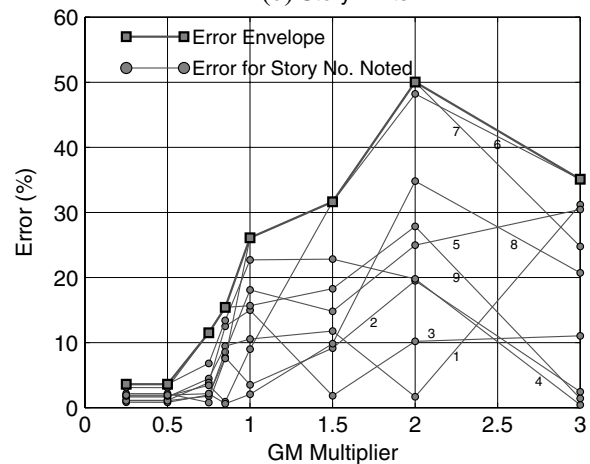

Figure 12. Errors in UMRHA as a function of ground motion intensity:

(a) floor displacements; and (b) storey drifts.

Figure 12 summarizes the error in UMRHA as a function of ground motion intensity, indicated by a ground motion multiplier. Shown is the error in each floor displacement [Figure 12(a)], in each storey drift [Figure 12(b)], and the error envelope for each case. To interpret these results, it will be useful to know the deformation of the system relative to its yield deformation. For this purpose, pushover curves using force distributions $\mathbf{s}_{n}^{*}$ [Equation (19)] for the first three modes of the system are shown in Figure 13, with the peak displacement of each 'modal' SDF system noted for each ground motion multiplier. Two versions of the pushover curve are included: the actual curve and its idealized bilinear version. The location of plastic hinges and their rotations, determined from 'exact' analyses, were noted but not shown here.

Figure 12 permits the following observations regarding the accuracy of the UMRHA procedure: the errors (i) are small (less than 5 per cent) for ground motion multipliers up 
(a) "Mode" 1 Pushover Curve

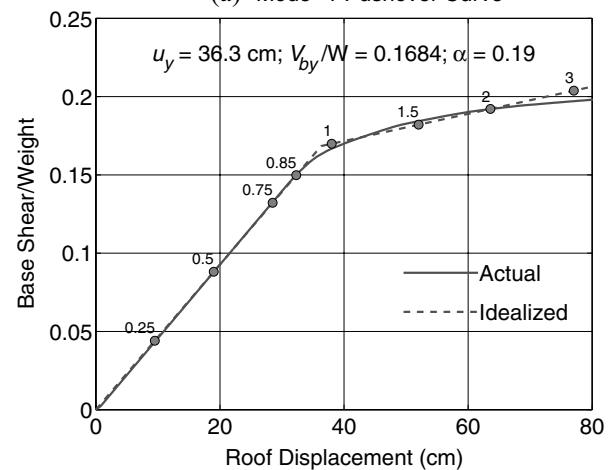

(b) "Mode" 2 Pushover Curve

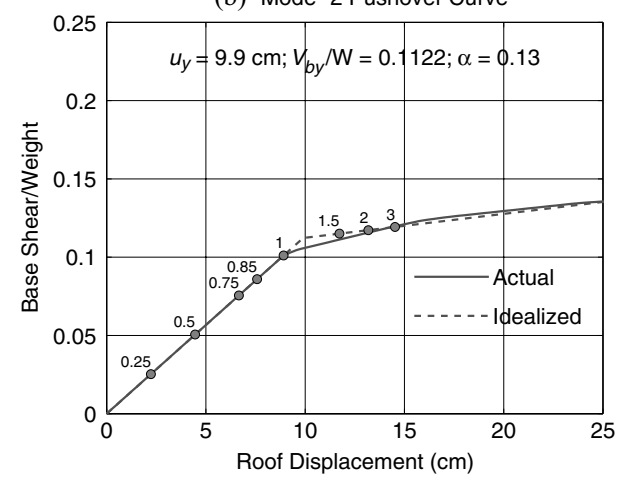

(c) "Mode" 3 Pushover Curve

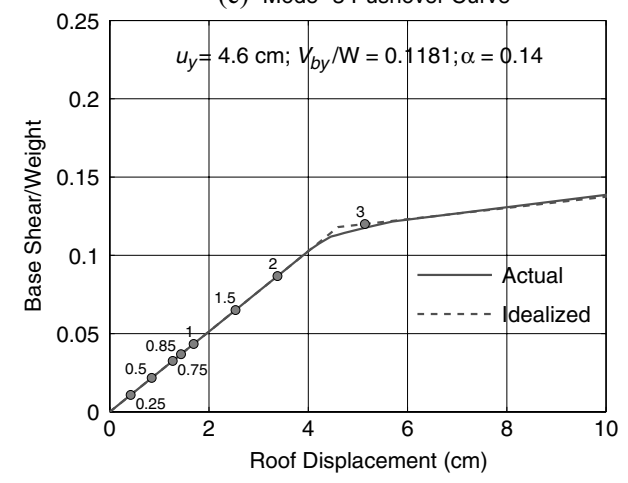

Figure 13. 'Modal' pushover curves with peak roof displacements identified for $0.25,0.5,0.75,1.0$, $1.5,2.0$, and $3.0 \times$ El Centro ground motion.

to 0.75 ; (ii) increase rapidly as the ground motion multiplier increases to 1.0 ; (iii) maintain roughly similar values for more intense ground motions; and (iv) are larger in storey drifts compared to floor displacements. Up to ground motion multiplier 0.75 , the system remains elastic and the errors in truncating the higher mode contributions are negligible. Additional errors are introduced in UMRHA of systems responding beyond the linearly elastic limit for at least two reasons. First, as mentioned earlier, UMRHA lacks a rigorous theory and is based on several approximations. Second, the pushover curve for each 'mode' is idealized by a bilinear curve in solving Equation (28) for each 'modal' inelastic SDF system (Figures 6 and 13). The idealized curve for the first 'mode' deviates most from the actual curve near the peak displacement corresponding to ground motion multiplier 1.0. This would explain why the errors are large at this excitation intensity; although the system remains essentially elastic; the ductility factor for the first mode system is only 1.01 [Figure 13(a)]. For more intense excitations, the first reason mentioned above seems to be the primary source for the errors.

\section{Modal pushover analysis}

The MPA procedure, considering the response due to the first three 'modes', was implemented for the selected building subjected to $1.5 \times$ the El Centro ground motion. The struc- 
(a) Floor Displacements

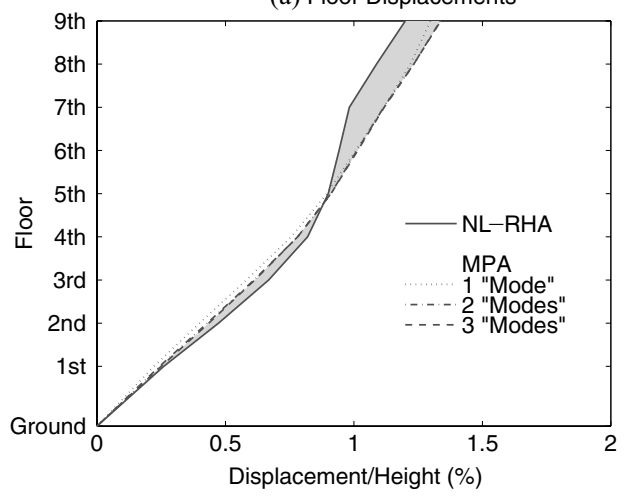

(b) Story Drift Ratios

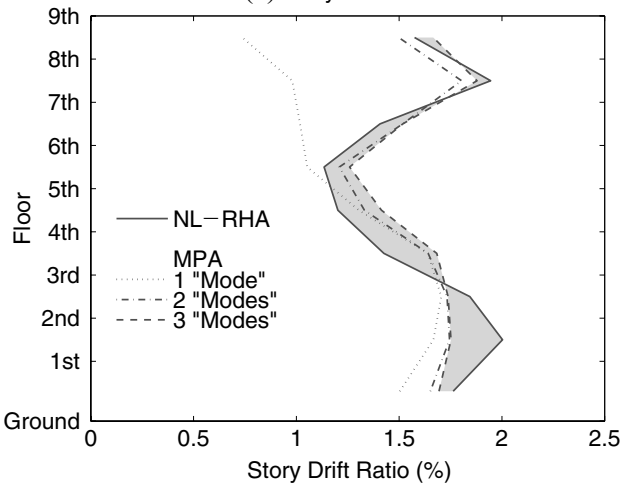

Figure 14. Height-wise variation of floor displacements and storey drift ratios from MPA and non-linear RHA for $1.5 \times$ El Centro ground motion; shading indicates errors in MPA including three 'modes'.

ture is pushed using the force distribution of Equation (19) with $n=1,2$ and 3 (Figure 8) to roof displacements $u_{r n o}=48.3,11.7$ and $2.53 \mathrm{~cm}$, respectively, the values determined by RHA of the $n$ th-mode inelastic SDF system (Figure 9). Each of these three pushover analyses provides the pushover curve (Figure 13) and the peak values of modal responses. Because this building is unusually strong - its yield base shear $=16.8$ per cent of the building weight [Figure 13(a)] - the displacement ductility demand imposed by three times the El Centro ground motion is only slightly larger than 2 . Figure 14 presents estimates of the combined response according to Equation (17), considering one, two, and three 'modes', respectively, and Figure 15 shows the errors in these estimates relative to the exact response from non-linear RHA. The errors in the modal pushover results for two or three modes included are generally significantly smaller than in UMRHA (compare Figures 15 and 11). Obviously, the additional errors due to the approximation inherent in modal combination rules tend to cancel out the errors due to the various approximation contained in the UMRHA. The first 'mode' alone is inadequate, especially in estimating the storey drifts (Figure 14). Significant improvement is achieved by including response contributions due to the second 'mode', however, the third 'mode' contributions do not seem especially important (Figure 14). As shown in Figure 15(a), MPA including three 'modes' underestimates the displacements of the lower floors by up to 8 per cent and overestimates the upper floor displacements by up to 14 per cent. The drifts are underestimated by up to 13 per cent in the lower storeys, overestimated by up to 18 per cent in the middle storeys, and are within a few per cent of the exact values for the upper storeys [Figure 15(b)].

The errors are especially large in the hinge plastic rotations estimated by the MPA procedures, even if three 'modes' are included [Figure 15(c)]; although the error is recorded as 100 per cent if MPA estimates zero rotation when the non-linear RHA computes a non-zero value, this error is not especially significant because the hinge plastic rotation is very small. Observe that the primary contributor to plastic rotations of hinges in the lower storeys is the first 'mode', in the upper storeys it is the second 'mode'; the third 'mode' does not contribute because this SDF system remains elastic [Figure 13(c)]. 
(a) Floor Displacements

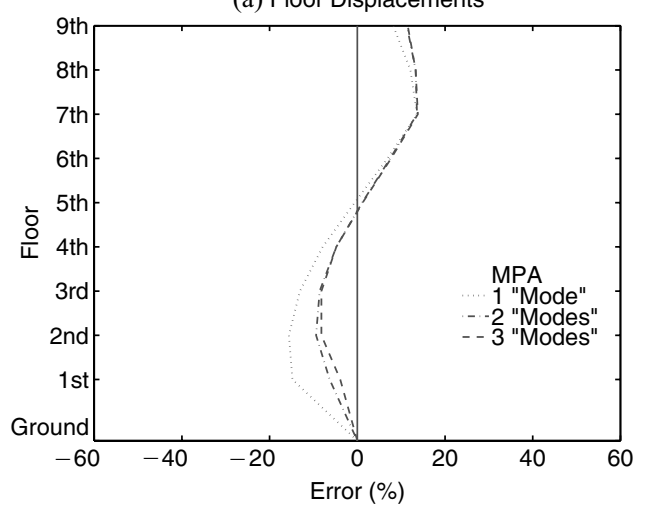

(b) Story Drift Ratios

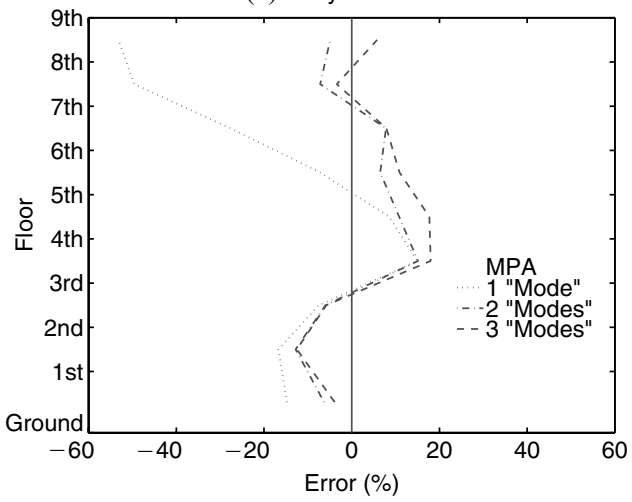

(c) Hinge Plastic Rotations

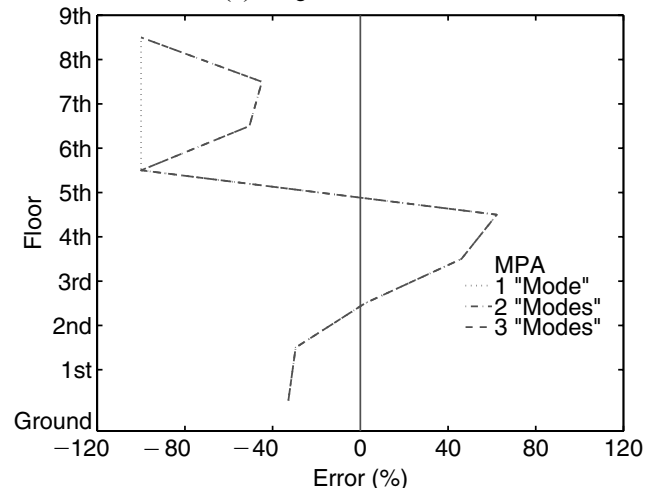

Figure 15. Errors in floor displacements, storey drifts, and hinge plastic rotations estimated by MPA including one, two and three 'modes' for $1.5 \times$ El Centro ground motion.

The locations of plastic hinges shown in Figure 16 were determined by four analyses: MPA considering one 'mode', two 'modes', and three 'modes'; and non-linear RHA. One 'mode' pushover analysis is unable to identify the plastic hinges in the upper storeys where higher mode contributions to response are known to be more significant. The second 'mode' is necessary to identify hinges in the upper storeys, however, the results are not always accurate. For example, the hinges identified in beams at the sixth floor are at variance with the 'exact' results. Furthermore, MPA failed to identify the plastic hinges at the column bases in Figure 16, but was successful when the excitation was more intense.

Figure 17 summarizes the error in MPA considering three 'modes' as a function of ground motion intensity, indicated by a ground motion multiplier. Shown is the error in each floor displacement [Figure 17(a)], each storey drift [Figure 17(b)], and the error envelope for each case. While various sources of errors in UMRHA also apply to MPA, the errors in MPA are fortuitously smaller than in UMRHA (compare Figures 17 and 12) for ground motion multipliers larger than 1.0, implying excitations intense enough to cause significant yielding of the structure. However, errors in MPA are larger for ground motion multipliers less than 
(a) MPA, 1_"Mode"

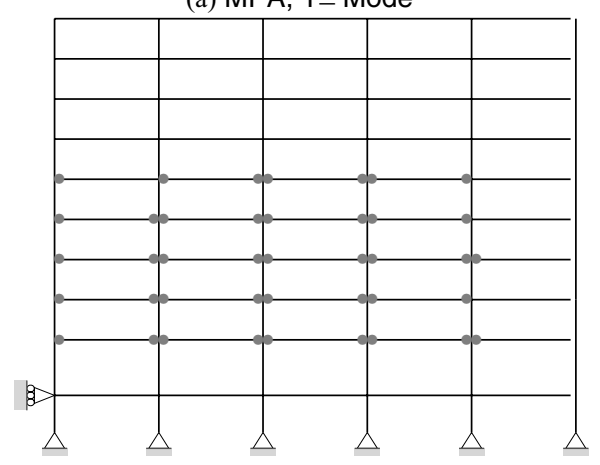

(c) 3-"Modes"

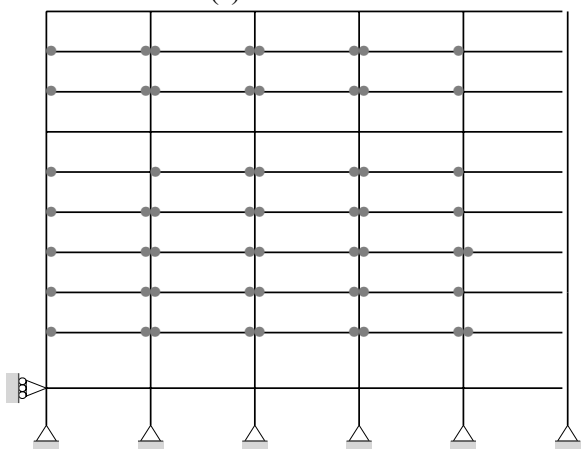

(b) MPA, 2-"Modes"

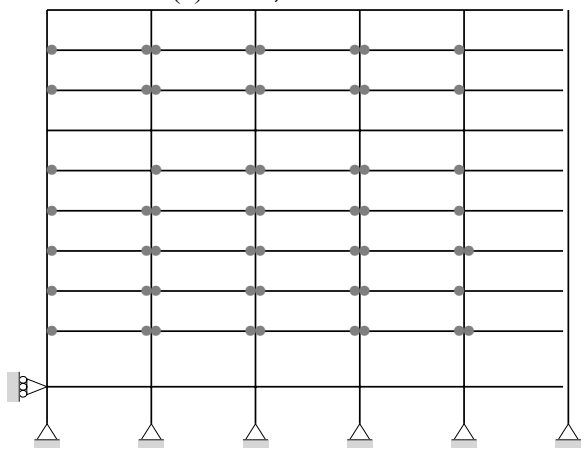

(d) Nonlinear RHA

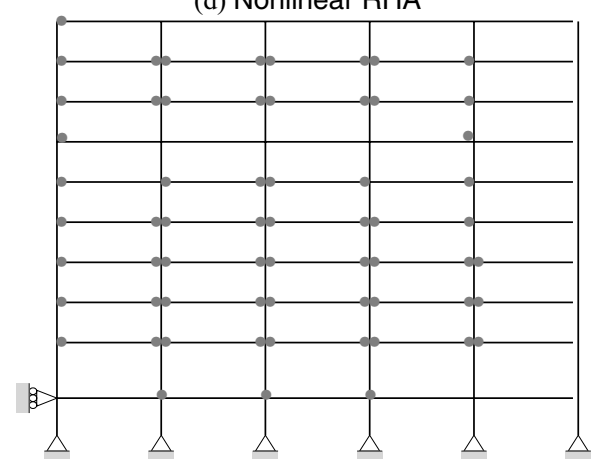

Figure 16. Locations of plastic hinges determined by MPA considering one, two and three 'modes' and by non-linear RHA for $1.5 \times$ El Centro ground motion.

(a) Floor Displacements

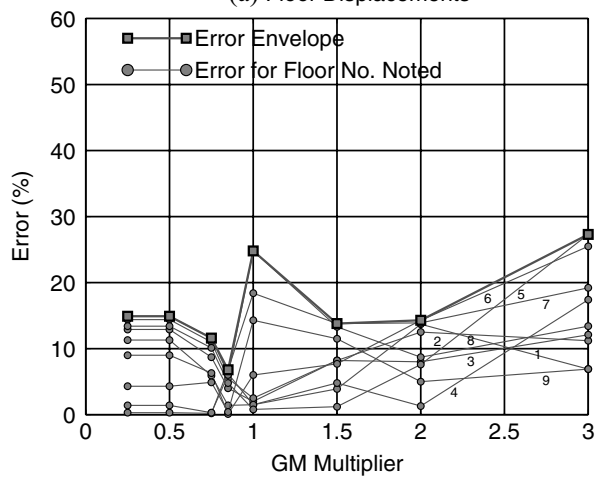

(b) Story Drifts

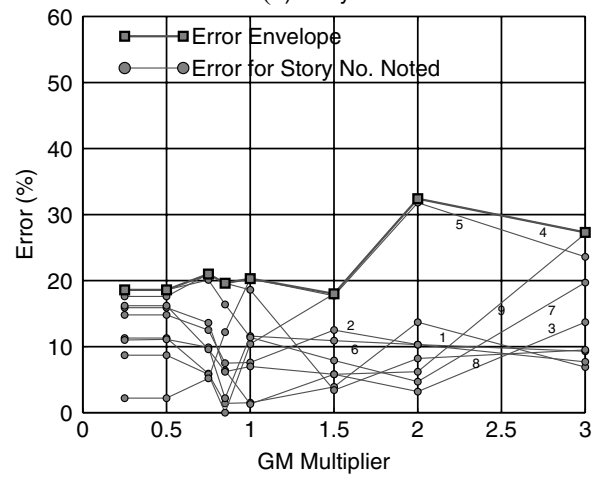

Figure 17. Errors in MPA as a function of ground motion intensity: (a) floor displacements; and (b) storey drifts. 
0.75, implying excitations weak enough to limit the response in the elastic range of the structure. Here, UMRHA is essentially exact, whereas MPA contains errors inherent in modal combination rules.

The errors are only weakly dependent on ground motion intensity (Figure 17), an observation with practical implications. As mentioned earlier, the MPA procedure for elastic systems (or weak ground motions) is equivalent to the RSA procedure-now standard in engineering practice-implying that the modal combination errors contained in these procedures are acceptable. The fact that MPA is able to estimate the response of buildings responding well into the inelastic range to a similar degree of accuracy indicates that this procedure is accurate enough for practical application in building retrofit and design.

\section{CONCLUSIONS}

This investigation aimed to develop an improved pushover analysis procedure based on structural dynamics theory, which retains the conceptual simplicity and computational attractiveness of current procedures with invariant force distribution now common in structural engineering practice. It has led to the following conclusions:

The standard response spectrum analysis for elastic multistorey buildings can be reformulated as a modal pushover analysis (MPA). The peak response of the elastic structure due to its $n$th vibration mode can be exactly determined by pushover analysis of the structure subjected to lateral forces distributed over the height of the building according to $\mathbf{s}_{n}^{*}=\mathbf{m} \boldsymbol{\phi}_{n}$, where $\mathbf{m}$ is the mass matrix and $\phi_{n}$ its $n$ th-mode, and the structure is pushed to the roof displacement determined from the peak deformation $D_{n}$ of the $n$ th-mode elastic SDF system; $D_{n}$ is available from the elastic response (or design) spectrum. Combining these peak modal responses by an appropriate modal combination rule (e.g. SRSS rule) leads to the MPA procedure.

The MPA procedure developed to estimate the seismic demands on inelastic systems is organized in two phases: First, a pushover analysis is used to determine the peak response $r_{n o}$ of the inelastic MDF system to individual terms, $\mathbf{p}_{\text {eff }, n}(t)=-\mathbf{s}_{n} \ddot{u}_{g}(t)$, in the modal expansion of the effective earthquakes forces, $\mathbf{p}_{\mathrm{eff}}(t)=-\mathbf{m} \boldsymbol{\imath} \ddot{u}_{g}(t)$. The base shear-roof displacement $\left(V_{b n}-\right.$ $\left.u_{r n}\right)$ curve is developed from a pushover analysis for the force distribution $\mathbf{s}_{n}^{*}$. This pushover curve is idealized as a bilinear force-deformation relation for the $n$ th-'mode' inelastic SDF system (with vibration properties in the linear range that are the same as those of the $n$ thmode elastic SDF system), and the peak deformation of this SDF system-determined by nonlinear response history analysis (RHA) or from the inelastic response or design spectrum - is used to determine the target value of roof displacement at which the seismic response $r_{n o}$ is determined by the pushover analysis. Second, the total demand $r_{o}$ is determined by combining the $r_{n o}(n=1,2, \ldots)$ according to an appropriate modal combination rule (e.g. SRSS rule).

Comparing the peak inelastic response of a 9-storey SAC steel building determined by the approximate MPA procedure - including only the first two or three $r_{n o}$ terms - with nonlinear RHA demonstrated that the approximate procedure provided good estimates of floor displacements and storey drifts, and identified locations of most plastic hinges; however, plastic hinge rotations were less accurate. Based on results presented for El Centro ground motion scaled by factors varying from 0.25 to 3.0 , MPA estimates the response of buildings responding well into the inelastic range to similar degree of accuracy as standard RSA is capable of estimating peak response of elastic systems. Thus, the MPA procedure is accurate 
enough for practical application in building evaluation and design. That said, however, all pushover analysis procedures considered do not seem to compute accurately local response quantities, such as hinge plastic rotations.

Thus the structural engineering profession should examine the present trend of comparing computed hinge plastic rotations against rotation limits established in FEMA-273 to judge structural performance. Perhaps structural performance evaluation should be based on storey drifts that are known to be closely related to damage and can be estimated to a higher degree of accuracy by pushover analyses. While pushover estimates for floor displacements are even more accurate, they are not good indicators of damage.

This paper has focused on developing an MPA procedure and its initial evaluation in estimating the seismic demands on a building imposed by a selected ground motion, with the excitation scaled to cover a wide range of ground motion intensities and building response. This new method for estimating seismic demands at low performance levels, such as life safety and collapse prevention, should obviously be evaluated for a wide range of buildings and ground motion ensembles. Work along these lines is in progress.

\section{APPENDIX A: SAC STEEL BUILDING}

The 9-storey structure, shown in Figure A1, was designed by Brandow \& Johnston Associates $^{\S}$ for the SAC Phase II Steel Project. Although not actually constructed, this structure meets seismic code requirements of the 1994 UBC and represents typical medium-rise buildings designed for the Los Angeles, California, region.

A benchmark structure for the SAC project, this building is $45.73 \mathrm{~m}(150 \mathrm{ft})$ by $45.73 \mathrm{~m}$ $(150 \mathrm{ft})$ in plan, and $37.19 \mathrm{~m}(122 \mathrm{ft})$ in elevation. The bays are $9.15 \mathrm{~m}(30 \mathrm{ft})$ on centre, in both directions, with five bays each in the north-south $(\mathrm{N}-\mathrm{S})$ and east-west $(\mathrm{E}-\mathrm{W})$ directions. The building's lateral force-resisting system is composed of steel perimeter moment-resisting frames (MRF). To avoid biaxial bending in corner columns, the exterior bay of the MRF has only one moment-resisting connection. The interior bays of the structure contain frames with simple (shear) connections. The columns are $345 \mathrm{MPa}(50 \mathrm{ksi})$ steel wide-flange sections. The levels of the 9-storey building are numbered with respect to the ground level (see Figure A1) with the ninth level being the roof. The building has a basement level, denoted B-1. Typical floor-to-floor heights (for analysis purposes measured from centre-of-beam to centre-of-beam) are $3.96 \mathrm{~m}(13 \mathrm{ft})$. The floor-to-floor height of the basement level is $3.65 \mathrm{~m}(12 \mathrm{ft})$ and for the first floor is $5.49 \mathrm{~m}(18 \mathrm{ft})$.

The column lines employ two-tier construction, i.e. monolithic column pieces are connected every two levels beginning with the first level. Column splices, which are seismic (tension) splices to carry bending and uplift forces, are located on the first, third, fifth, and seventh levels at $1.83 \mathrm{~m}(6 \mathrm{ft})$ above the centreline of the beam to column joint. The column bases are modelled as pinned and secured to the ground (at the B-1 level). Concrete foundation walls and surrounding soil are assumed to restrain the structure at the ground level from horizontal displacement.

\footnotetext{
$\S$ Brandow \& Johnston Associates, Consulting Structural Engineers, 1660 W. Third St., Los Angeles, CA 90017. I SAC is a joint venture of three non-profit organizations: The Structural Engineers Association of California (SEAOC), the Applied Technology Council (ATC), and California Universities for Research in Earthquake Engineering (CUREE). SAC Steel Project Technical Office, 1301 S. 46th Street, Richmond, CA 94804-4698.
} 
Building Plan

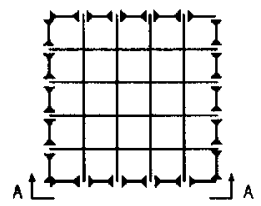

\section{Elevation}

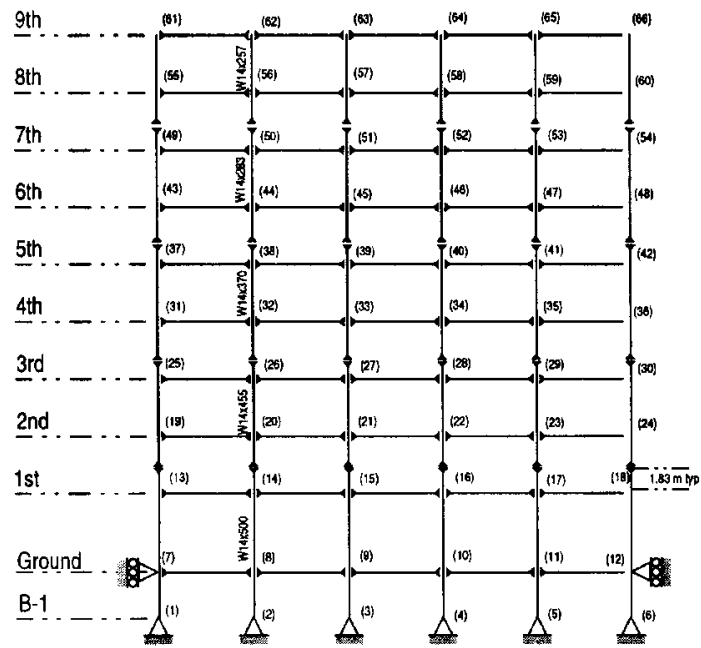

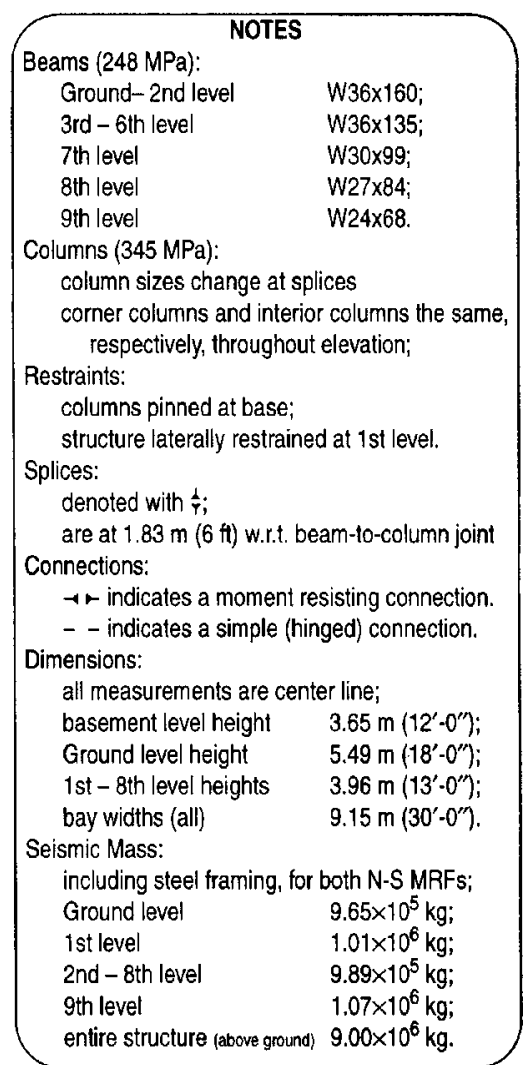

Figure A1. Nine-storey building (adapted from Reference [23]).

The floor system is composed of $248 \mathrm{MPa}$ (36 ksi) steel wide-flange beams in acting composite action with the floor slab. The seismic mass of the structure is due to various components of the structure, including the steel framing, floor slabs, ceiling/flooring, mechanical/electrical, partitions, roofing and a penthouse located on the roof. The seismic mass of the ground level is $9.65 \times 10^{5} \mathrm{~kg}\left(66.0 \mathrm{kips}-\mathrm{s}^{2} / \mathrm{ft}\right)$, for the first level is $1.01 \times 10^{6} \mathrm{~kg}$ $\left(69.0 \mathrm{kips}-\mathrm{s}^{2} / \mathrm{ft}\right)$, for the second through eighth levels is $9.89 \times 10^{5} \mathrm{~kg}\left(67.7 \mathrm{kips}-\mathrm{s}^{2} / \mathrm{ft}\right)$, and for the ninth level is $1.07 \times 10^{6} \mathrm{~kg}\left(73.2 \mathrm{kips}-\mathrm{s}^{2} / \mathrm{ft}\right)$. The seismic mass of the above ground levels of the entire structure is $9.00 \times 10^{6} \mathrm{~kg}\left(616 \mathrm{kips}-\mathrm{s}^{2} / \mathrm{ft}\right)$.

The two-dimensional building model consists of the perimeter N-S MRF (Figure A1), representing half of the building in the $\mathrm{N}-\mathrm{S}$ direction. The frame is assigned half of the seismic mass of the building at each floor level. The model is implemented in DRAIN-2DX [20] using the M1 model developed by Gupta and Krawinkler [7]. The MI model is based on centreline dimensions of the bare frame in which beams and columns extend from centreline to centreline. The strength, dimension, and shear distortion of panel zones are neglected but large deformation $(P-\Delta)$ effects are included. The simple model adopted here is sufficient for the objectives of this study; if desired, more complex models, such as those described in Reference [7], can be used. 


\section{ACKNOWLEDGEMENT}

This research investigation is funded by the National Science Foundation under Grant CMS-9812531, a part of the U.S.-Japan Co-operative Research in Urban Earthquake Disaster Mitigation. This financial support is gratefully acknowledged.

\section{REFERENCES}

1. Building Seismic Safety Council. NEHRP Guidelines for the Seismic Rehabilitation of Buildings, FEMA-273. Federal Emergency Management Agency: Washington, DC, 1997.

2. Saiidi M, Sozen MA. Simple non-linear seismic analysis of R/C structures. Journal of Structural Division, ASCE 1981; 107(ST5):937-951.

3. Miranda E. Seismic evaluation and upgrading of existing buildings. Ph.D. Dissertation, Department of Civil Engineering, University of California, Berkeley, CA, 1991.

4. Lawson RS, Vance V, Krawinkler H. Nonlinear static pushover analysis - why, when and how? Proceedings of the 5th U.S. Conference on Earthquake Engineering 1994; 1:283-292.

5. Fajfar P, Gaspersic P. The N2 method for the seismic damage analysis of RC buildings. Earthquake Engineering \& Structural Dynamics 1996; 25(1):31-46.

6. Maison B, Bonowitz D. How safe are pre-Northridge WSMFs? A case study of the SAC Los Angeles nine-storey building. Earthquake Spectra 1999; 15(4):765-789.

7. Gupta A, Krawinkler H. Seismic demands for performance evaluation of steel moment resisting frame structures (SAC Task 5.4.3). Report No. 132, John A. Blume Earthquake Engineering Center, Stanford University, CA, 1999.

8. Gupta A, Krawinkler H. Estimation of seismic drift demands for frame structures. Earthquake Engineering \& Structural Dynamics 2000; 29:1287-1305.

9. Skokan MJ, Hart GC. Reliability of non-linear static methods for the seismic performance prediction of steel frame buildings. Proceedings of the 12th World Conference on Earthquake Engineering, Paper No. 1972, Auckland, New Zealand, 2000.

10. Krawinkler H, Seneviratna GDPK. Pros and cons of a pushover analysis of seismic performance evaluation. Engineering Structures 1998; 20(4-6):452-464.

11. Bracci JM, Kunnath SK, Reinhorn AM. Seismic performance and retrofit evaluation for reinforced concrete structures. Journal of Structural Engineering, ASCE 1997; 123(1):3-10.

12. Gupta B, Kunnath SK. Adaptive spectra-based pushover procedure for seismic evaluation of structures. Earthquake Spectra 2000; 16(2):367-392.

13. Paret TF, Sasaki KK, Eilbekc DH, Freeman SA. Approximate inelastic procedures to identify failure mechanisms from higher mode effects. Proceedings of the 11th World Conference on Earthquake Engineering. Paper No. 966, Acapulco, Mexico, 1996.

14. Sasaki KK, Freeman SA, Paret TF. Multimode pushover procedure (MMP) - a method to identify the effects of higher modes in a pushover analysis. Proceedings of the 6th U.S. National Conference on Earthquake Engineering, Seattle, Washington, 1998.

15. Kunnath SK, Gupta B. Validity of deformation demand estimates using non-linear static procedures. Proceedings U.S.-Japan Workshop on Performance-Based Engineering for Reinforced Concrete Building Structures, Sapporo, Hokkaido, Japan, 2000.

16. Matsumori T, Otani S, Shiohara H, Kabeyasawa T. Earthquake member deformation demands in reinforced concrete frame structures. Proceedings U.S.-Japan Workshop on Performance-Based Earthquake Engineering Methodology for R/C Building Structures. Maui, Hawaii, 1999; 79-94.

17. Chopra AK. Dynamics of Structures: Theory and Applications to Earthquake Engineering. Prentice-Hall: Englewood Cliffs, NJ, 2001.

18. Villaverde R. Simplified response spectrum seismic analysis of non-linear structures. Journal of Structural Engineering Mechanics, ASCE 1996; 122:282-285.

19. Han SW, Wen YK. Method of reliability-based seismic design. I: Equivalent non-linear system. Journal of Structural Engineering, ASCE 1997; 123:256-265.

20. Allahabadi R, Powell GH. DRAIN-2DX user guide. Report No. UCB/EERC-88/06, Earthquake Engineering Research Center, University of California, Berkeley, CA, 1988.

21. Chopra AK, Goel R. Modal pushover analysis of SAC building, Proceedings SEAOC Convention, San Diego, California, 2001.

22. Chopra AK, Goel R. A modal pushover analysis procedure to estimate seismic demands for buildings: theory and preliminary evaluation. Report No. PEER 2001/03, Pacific Earthquake Engineering Research Center, University of California, Berkeley, CA, 2001.

23. Ohtori Y, Christenson RE, Spencer Jr BF, Dyke SJ. Benchmark Control Problems for Seismically Excited Nonlinear Buildings, http://www.nd.edu/ $\sim$ quake/, Notre Dame University, Indiana, 2000. 